International Journal of Pure and Applied Mathematics

Volume 114 No. 3 2017, 503-514

ISSN: 1311-8080 (printed version); ISSN: 1314-3395 (on-line version)

url: http://www.ijpam.eu

doi: 10.12732/ijpam.v114i3.7

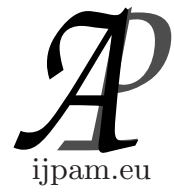

\title{
COST-BENEFIT ANALYSIS OF TWO IDENTICAL WARM STANDBY SYSTEM SUBJECT TO UNDER HEAVY RAIN WITH PARTIALLY OPERATIVE AFTER REPAIR
}

\author{
Narender Singh ${ }^{1}$, Dalip Singh ${ }^{2}$, Ashok Kumar Saini ${ }^{3}$ \\ ${ }^{1,2}$ Department of Mathematics \\ M.D. University \\ Rohtak, 124001, INDIA \\ ${ }^{3}$ Department of Mathematics \\ B.L.J.S. College
}

Tosham, Bhiwani, 127040, INDIA

\begin{abstract}
The aim of this paper is to improve the reliability through regenerative point technique. In this paper two identical units in the warm standby system are considered. The standby component is referred as 'warm standby' when the failure rate is nonzero and is less than the failure rate of a primary component. Each unit of the system has three modes via; operative, failed and partially operative. The failure and repair times follow exponential and general time distributions respectively. We transform the basic equations of the proposed model into an integro-differential equations and solve it by semi-Markov processes. Using the regeneration point technique several reliability characteristics have been obtained. Various reliability parameters such as mean time to system failure, availability, busy period, number of visit periods by repairman and profit have been computed and analyzed by graphical illustrations.
\end{abstract}

AMS Subject Classification: 47H09, 47H10

Key Words: similar warm stand by system, operative, partially operative and failed

\section{Introduction}

To improve the reliability of the systems many researchers have been worked on

Received: December 8, 2016

Revised: $\quad$ February 3, 2017

Published: $\quad$ May 23, 2017

(c) 2017 Academic Publications, Ltd. url: www.acadpubl.eu

$\S$ Correspondence author 
the reliability modeling. Osaki [4] and Taneja et al. [7] investigated reliability models of such systems with different failure rate and different repair facilities. Tuteja and Taneja [6] worked on warm standby system. Singh and Taneja [5], and Malhotra and Taneja [3] studied comparative study of the systems. Environmental conditions cannot be control which may fluctuate due to changing climate. Therefore, Goel and Sharma [1], Gupta and Goel [2] have obtained reliability measures of cold standby repairable systems operating under different weather conditions. Unprecedented heavy rain that hits Chennai city and other part of Tamilnadu during December 2015. All flight operations at Chennai airport had been partially suspended until further review and a number of flights have been disrupted as waters inundated the runway and the tarmac. SpiceJet and Indigo said the airfield had been closed due to flooding. While considering above facts and practical situations in mind, here reliability measures of a system of identical units operating under heavy rain obtained using semi-Markov process and regenerative point technique. In such situation we can improve the reliability of the system to first repair the system become partially operative after the repair of partially operative unit the system become operative.

Briefly mentioned all sections and subsections.

Model and transition probabilities and mean sojourn times have been developed and they are given below:

- Mean Times to system failure

- availability analysis

- busy period analysis of the repairman

- expected number of visits by the repairman

- profit analysis

- particular cases

The assumptions for the model are given below:

- both units are identical

- Starting the unit is not partially fail but after repair the unit becomes partially operative

- Only one repairman with the system 


\section{Notations}

$\lambda_{1}$

$\lambda_{2}$

○

$G_{1}(t), g_{1}(t) \quad$ : $\quad$ C.d.f. and P.d.f. of the repair time of failure unit to partially operative

$G_{2}(t), g_{2}(t) \quad$ : C.d.f. and P.d.f. of the repair time of partially operative to operative unit

Op : operative unit

ws : warn standby unit

Fur $_{1} \quad$ : failure unit is under repair from the stage 1

Fur $_{2} \quad$ : failure unit is under repair from the stage 2

PouR $_{1} \quad$ : partial operative unit is under repair is continuing from the stage 1

$\mathrm{PouR}_{2} \quad$ : partial operative repair is under repair is continuing from the stage 2

$\mathrm{FuR}_{1} \quad$ : repair is continuing on failed unit from the stage 1

$\mathrm{FuR}_{2} \quad$ : repair is continuing on failed unit from the stage 2

Fwr : waiting for repair

\section{Transition Probabilities and Mean Sojourn Times}

The epochs of entry into states 0,1 and 2 regenerative points and thus these are regenerative states. States $3,4,5,6,7$ and 8 are non regenerative states.

The non zero elements $p_{i j}$ of the transition probability for the system are found out as

$$
\begin{aligned}
& p_{i j}=\lim _{s \rightarrow 0} q_{i j}^{*}(s) \\
& p_{01}=\lambda_{1} /\left(\lambda_{2}+\lambda_{1}\right), p_{02}=\lambda_{2} /\left(\lambda_{2}+\lambda_{1}\right), p_{18}=g_{1}^{*}\left(\lambda_{1}\right), p_{13}=\left(1-g_{1}^{*}\left(\lambda_{1}\right)\right)
\end{aligned}
$$




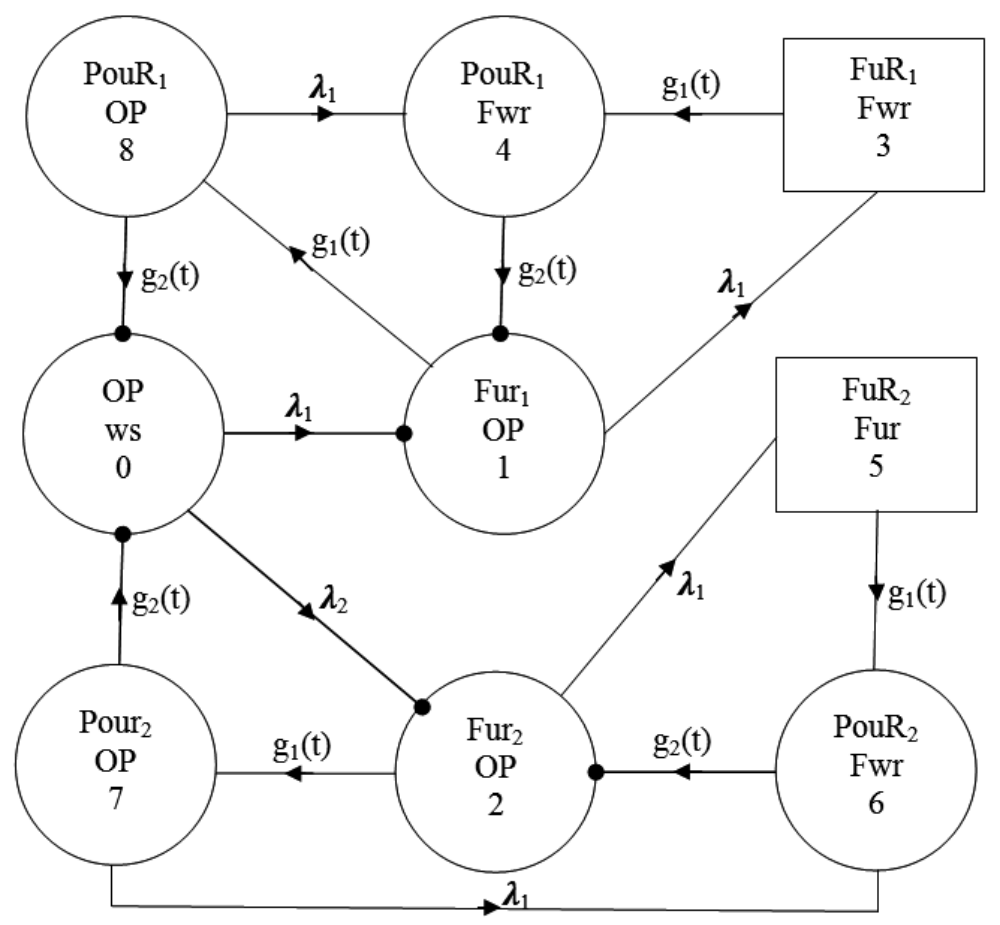

Figure 1: State Transition Diagram

$$
\begin{aligned}
& p_{34}=g_{1}^{*}(0), p_{41}=g_{2}^{*}(0), p_{27}=g_{1}^{*}\left(\lambda_{1}\right), p_{25}=\left(1-g_{1}^{*}\left(\lambda_{1}\right)\right) \\
& p_{70}=g_{2}^{*}\left(\lambda_{1}\right), p_{76}=\left(1-g_{2}^{*}\left(\lambda_{1}\right)\right), p_{80}=g_{2}^{*}\left(\lambda_{1}\right), p_{84}=\left(1-g_{2}^{*}\left(\lambda_{1}\right)\right) \\
& p_{56}=g_{1}^{*}(0), p_{62}=g_{2}^{*}(0) \\
& p_{10}^{8}=g_{1}^{*}\left(\lambda_{1}\right), g_{2}^{*}\left(\lambda_{1}\right), p_{11}^{84}=g_{1}^{*}\left(\lambda_{1}\right)\left(1-g_{2}^{*}\left(\lambda_{1}\right)\right), p_{11}^{34}=\left(1-g_{1}^{*}\left(\lambda_{1}\right)\right) \\
& p_{20}^{7}=g_{1}^{*}\left(\lambda_{1}\right) g_{2}^{*}\left(\lambda_{1}\right), p_{22}^{76}=g_{1}^{*}\left(\lambda_{1}\right)\left(1-g_{2}^{*}\left(\lambda_{1}\right)\right), p_{22}^{5} 6=\left(1-g_{1}^{*}\left(\lambda_{2}\right)\right)
\end{aligned}
$$

For the transition probabilities, it can be verified that

$$
\begin{aligned}
& p_{01}+p_{02}=1 \\
& p_{10}^{8}+p_{11}^{84}+p_{11}^{34}=1 \\
& p_{20}^{7}+p_{22}^{56}+p_{22}^{76}=1
\end{aligned}
$$

The mean sojourn times $\mu_{i}$ in state ' $i$ ' are given by

$$
\mu_{0}=1 /\left(\lambda_{2}+\lambda_{1}\right), \mu_{1}=1 / \lambda_{1}\left(1-g_{1}^{*}\left(\lambda_{1}\right)\right), \mu_{2}=1 / \lambda_{1}\left(1-g_{1}^{*}\left(\lambda_{1}\right)\right)
$$


the unconditional mean time taken by the system to transit from any state ' $i$ ' when time is counted from epoch at entrance into state ' $i$ ' is stated as:

$$
m_{i j}=\int_{0}^{\infty} t q_{i j}(t) d t=-q_{i j}^{*^{\prime}}(0)
$$

Thus,

$$
\begin{aligned}
& m_{01}+m_{02}=\mu_{0}, m_{13}=g_{1}^{* 1}\left(\lambda_{1}\right)+1 / \lambda_{1}\left(1-g_{1}^{*}\left(\lambda_{1}\right)\right), \\
& m_{18}=-g_{1}^{* 1}\left(\lambda_{1}\right), m_{27}=-g_{1}^{* 1}\left(\lambda_{1}\right), \\
& m_{25}=g_{1}^{* 1}\left(\lambda_{1}\right)+1 / \lambda_{1}\left(1-g_{1}^{*}\left(\lambda_{1}\right)\right), m_{34}=-g_{1}^{* 1}(0), \\
& m_{41}=-g_{2}^{* 1}(0), m_{56}=-g_{1}^{* 1}(0), m_{62}=-g_{2}^{* 1}(0), \\
& m_{76}=g_{1}^{* 1}\left(\lambda_{1}\right)+1 / \lambda_{1}\left(1-g_{1}^{*}\left(\lambda_{1}\right)\right), m_{70}=-g_{2}^{* 1}\left(\lambda_{1}\right), \\
& m_{84}=g_{1}^{* 1}\left(\lambda_{1}\right)+1 / \lambda_{1}\left(1-g_{1}^{*}\left(\lambda_{1}\right)\right), m_{80}=-g_{2}^{* 1}\left(\lambda_{1}\right), \\
& m_{10}^{8}+m_{11}^{84}+m_{13}=K \\
& m_{10}^{8}+m_{11}^{84}+m_{11}^{34}=K_{1}
\end{aligned}
$$

\section{Analysis of Mean Time to System Failure}

Regarding the failed states as absorbing states and applying the arguments used for regenerative processes, the following recursive relation for $\phi_{i}(t)$ are obtained

$$
\begin{aligned}
& \phi_{0}(t)=Q_{01}(t) \text { S } \phi_{1}(t)+Q_{02}(t) \text { S } \phi_{2}(t) \\
& \phi_{1}(t)=Q_{13}(t)+Q_{10}^{(8)}(t) \text { S } \phi_{0}(t)+Q_{11}^{(84)}(t) \text { S } \phi_{1}(t) \\
& \phi_{2}(t)=Q_{25}(t)+Q_{20}^{(7)}(t) \text { S } \phi_{0}(t)+Q_{22}^{(76)}(t) \text { S } \phi_{2}(t)
\end{aligned}
$$

Taking Laplace-Stieltjes Transforms (L.S.T) of these relations and solving them by Cramer's rule for $\phi_{0}^{* *}(s)$.

Now, the mean time to system failure (MTSF) when the system starts from the state ' 0 ' is

$$
\begin{aligned}
T_{0} & =\lim _{s \rightarrow 0} \frac{1-Q_{0}^{* *}(s)}{s}=\lim _{s \rightarrow 0} \frac{1-\frac{N(S)}{D(S)}}{s}=\lim _{s \rightarrow 0} \frac{D(s)-N(s)}{s D(s)} \\
& =\frac{D^{\prime}(0)-N^{\prime}(0)}{(D(0)}=\frac{N}{D}
\end{aligned}
$$

where $N=\left(1-p_{11}^{84}\right)\left(K+\mu_{0}\left(p_{10}^{8}+p_{13}\right)\right)$ and $D=\left(1-p_{11}^{84}\right) p_{11}^{34}$. 


\section{Availability Analysis}

The availability of a system is defined as the probability that the system is operating and provides service when requested.

Using the probabilistic argument and $A_{i}(t)$ as the probability of unit entering into up state at time $t$, given that the unit entered is regenerative state $i$ at $t=0$, the following recursive relation are obtained.

$$
\begin{aligned}
& A_{0}(t)=M_{0}(t)+q_{01}(t) \text { ( } A_{1}(t)+q_{02}(t) \text { ( } A_{2}(t) \\
& A_{1}(t)=M_{1}(t)+q_{10}^{(8)}(t) \text { ( } A_{0}(t)+\left(q_{11}^{(84)}(t)+q_{11}^{(34)}(t)\right) \text { ( } A_{1}(t) \\
& A_{2}(t)=M_{2}(t)+q_{20}^{(7)}(t) \text { (c) } A_{0}(t)+\left(q_{22}^{(76)}(t)+q_{22}^{(56)}(t)\right) \text { ( } A_{2}(t)
\end{aligned}
$$

where $M_{0}(t)=e^{-\left(\lambda_{1}+\lambda_{2}\right) t} d t, M_{1}(t)=e^{-\lambda_{1} t}\left(\bar{G}_{1}\right)(t) d t, M_{2}(t)=e^{-\lambda_{1} t}\left(\bar{G}_{1}\right)(t) d t$.

Taking Laplace transforms (L.T.) of these relations and solving them by Crammer rule for $A_{0}^{*}(s)$, we obtain

$$
A_{0}^{*}(s)=\frac{N_{1}(s)}{D_{1}(s)}
$$

where,

$$
\begin{aligned}
N_{1}(s)= & M_{0}^{*}(s)-M_{0}^{*}(s) q_{22}^{*(76)}(s)-M_{0}^{*}(s) q_{22}^{*(56)}(s) \\
& +M_{0}^{*}(s) q_{11}^{*(84)}(s) q_{22}^{*(76)}(s)+M_{0}^{*}(s) q_{11}^{*(34)}(s) q_{22}^{*(76)}(s) \\
& +M_{0}^{*}(s) q_{11}^{*(84)}(s) q_{22}^{*(56)}(s)+M_{0}^{*}(s) q_{11}^{*(34)}(s) q_{22}^{*(56)}(s) \\
& +M_{1}^{*}(s) q_{01}^{*}(s)-M_{1}^{*}(s) q_{01}^{*}(s) q_{22}^{*(76)}(s)+M_{2}^{*}(s) q_{02}^{*}(s) \\
& -M_{2}^{*}(s) q_{02}^{*}(s) q_{11}^{*(84)}(s)-M_{2}^{*}(s) q_{02}^{*}(s) q_{11}^{*(34)}(s) \\
& -M_{1}^{*}(s) q_{01}^{*}(s) q_{22}^{*(56)}(s) \\
D_{1}(s)= & 1-q_{22}^{*(76)}-q_{22}^{*(56)}(s)-q_{11}^{*(84)}(s)-q_{11}^{*(34)}(s) \\
& +q_{11}^{*(84)}(s) q_{22}^{*(76)}(s)+q_{11}^{* 84}(s) q_{22}^{*(56)}(s) \\
& +q_{11}^{*(34)}(s) q_{22}^{*(76)}(s)+q_{11}^{*(34)}(s) q_{22}^{*(56)}(s) \\
& -q_{01}^{*}(s) q_{10}^{*(8)}(s)+q_{01}^{*}(s) q_{10}^{*(8)}(s) q_{22}^{*(76)}(s) \\
& +q_{01}^{*}(s) q_{10}^{*(8)}(s) q_{22}^{*(56)}(s)-q_{02}^{*}(s) q_{10}^{*(7)}(s) \\
& +q_{02}^{*}(s) q_{10}^{*(7)}(s) q_{11}^{*(84)}(s)+q_{02}^{*}(s) q_{20}^{*(7)}(s) q_{11}^{*(34)}(s)
\end{aligned}
$$


The steady state availability of the system is given by

$$
\begin{aligned}
& A_{0}=\lim _{s \rightarrow 0}\left(s A_{0}^{*}(s)\right)=\lim _{s \rightarrow 0}\left(s \frac{N_{1}(s)}{D_{1}(s)}\right)=\frac{N_{1}(0)}{D_{1}^{\prime}(0)}=\frac{N_{1}}{D_{1}} \\
& N_{1}=\left(M_{0}+M_{0}\right) p_{10}^{(8)}+M_{0}\left(1-p_{10}^{(8)}\right)\left(1-p_{10}^{(8)}\right) \\
& D_{1}=p_{10}^{(8)}\left(K_{1}+\mu_{0} p_{10}^{(8)}\right)
\end{aligned}
$$

where, $K_{1}$ is already specified.

\section{Busy Period Analysis of the Repair Man}

$B_{i}(t)=$ Probability that the repair man is busy at instant $t$, given that the system entered regenerative state $i$ at $t=0$,

$$
\begin{aligned}
& B_{0}(t)=q_{01}(t) \text { ( } B_{1}(t)+q_{02}(t) \text { ( } B_{2}(t) \\
& B_{1}(t)=W_{1}(t)+q_{10}^{(8)}(t) \text { ( } B_{0}(t)+\left(q_{11}^{(84)}(t)+q_{11}^{(34)}(t)\right) \text { ( } B_{1}(t) \\
& B_{2}(t)=W_{2}(t)+q_{20}^{(7)}(t) \text { (c } B_{0}(t)+\left(q_{22}^{(76)}(t)+q_{22}^{(56)}(t)\right) \text { ( } B_{2}(t)
\end{aligned}
$$

where

$$
\begin{aligned}
& W_{1}(t)=e^{-\lambda_{1} t}\left(\bar{G}_{1}\right)(t) d t+\left(\lambda_{2} e^{-\lambda_{1} t} \text { C } 1\right)\left(\bar{G}_{1}\right)(t) d t \\
& W_{2}(t)=e^{-\lambda_{1} t}\left(\bar{G}_{1}\right)(t) d t+\left(\lambda_{1} e^{-\lambda_{1} t} \text { (C) } 1\right)\left(\bar{G}_{1}\right)(t) d t
\end{aligned}
$$

Taking Laplace transforms (L.T.) of these relations and solving them by applying crammer's rule for $B_{0}^{*}(s)$, we obtain

$$
B_{0}^{*}(s)=\frac{N_{2}(s)}{D_{1}(s)}
$$

where

$$
\begin{aligned}
N_{2}(s) & =q_{01}^{*}(s) W_{1}^{*}(s)\left(1+q_{01}^{*}(s) W_{1}^{*}(s)-q_{01}^{*}(s) W_{1}^{*}(s) q_{22}^{*(76)}(s)\right. \\
& -q_{01}^{*}(s) W_{1}^{*}(s) q_{22}^{*(56)}(s)+q_{01}^{*}(s) W_{2}^{*}(s)-q_{02}^{*}(s) W_{2}^{*}(s) q_{11}^{*(84)}(s) \\
& -q_{02}^{*}(s) W_{2}^{*}(s) q_{11}^{*(34)}(s)
\end{aligned}
$$

and $D_{1}(s)$ is already specified.

In steady state, the total fraction of time for which the system is under repair 1 is given by

$$
B_{0}=\lim _{s \rightarrow 0}\left(s B_{0}^{*}(s)\right)=\lim _{s \rightarrow 0}\left(\frac{s\left(N_{2}(s)\right.}{D_{1}(s)}\right)=\frac{N_{2}(0)}{D_{1}^{\prime}(0)}=\frac{N_{2}}{D_{1}}
$$


where, $N_{2}=W_{5} p_{1} 0^{(8)}, W_{1}=W_{1}^{*}(0)=W_{2}^{*}(0)$ and $D_{1}$ is already specified.

\section{Expected Number of Visits by the Repair Man}

We define $V_{0}(t)=$ expected number of visits by the repair man in $(0, t]$, given that the system started from the regenerative state $i$ at $t=0$

$$
\begin{aligned}
& V_{0}(t)=Q_{01}(t) \Subset\left(1+V_{1}(t)\right)+Q_{02}(t) \subseteq\left(1+V_{1}(t)\right) \\
& \left.V_{1}(t)=Q_{10}^{(8)}(t) \subseteq V_{0}(t)+\left(Q_{11}^{(84)}(t)+Q_{11}^{(34)}(t)\right) \text { (s } V_{1}(t)\right) \\
& V_{2}(t)=Q_{20}^{(7)}(t) \subseteq V_{0}(t)+\left(Q_{22}^{(76)}(t)+Q_{22}^{(56)}(t)\right) \subseteq V_{2}(t)
\end{aligned}
$$

Taking LaplaceStieltjes Transforms (L.S.T.) of these relations and solving them by applying crammer rule for $V_{0}^{* *}(s)$, we obtain

$$
V_{0}^{* *}(s)=\frac{N_{3}(s)}{D_{1}(s)}
$$

where

$$
\begin{aligned}
N_{3}(s)= & \left(Q_{01}^{* *}(s)+Q_{02}^{* *}(s)\right)\left(1-\left(Q_{11}^{* *(84)}(s)+Q_{11}^{* *(34)}(s)\right)\right. \\
& \left(1-\left(Q_{22}^{* *(76)}(s)+Q_{22}^{* *(56)}(s)\right)\right.
\end{aligned}
$$

and $D_{1}(s)$ is already specified.

$$
V_{0}=\lim _{s \rightarrow 0}\left(s V_{0}^{*}(s)\right)=\lim _{s \rightarrow 0}\left(\frac{s\left(N_{3}(s)\right)}{D_{1}(s)}\right)=\frac{N_{3}(0)}{D_{1}^{\prime}(0)}=\frac{N_{3}}{D_{1}}
$$

where $\left.N_{3}=1-p_{10}^{(8)} p_{10}^{(}(8)\right)$ and $D_{1}$ is already specified.

\section{Cost-Benefit Analysis}

The expected total profit incurred to the system in steady state is given by

$$
P=C_{0} A_{0}-C_{1} B_{0}-C_{2} V_{0}
$$

where

$C_{0}=$ revenue per unit up time of the system

$C_{1}=$ cost per unit time for which expert repairman is busy in repairing in the field unit

$C_{2}=$ cost per visit of expert. 


\section{Graphical Study}

Let us assume that the repair rate are exponentially distributed as under:

$$
\begin{aligned}
& g_{1}(t)=\alpha_{1} e^{-\alpha_{1} t} \text { and } g_{2}(t)=\alpha_{2} e^{-\alpha_{2} t} \\
& p_{01}=\lambda_{1} /\left(\lambda_{2}+\lambda_{1}\right), p_{18}=\lambda_{2} /\left(\lambda_{2}+\lambda_{1}\right), \\
& p_{13}=\lambda_{1} /\left(\lambda_{2}+\alpha_{1}\right), p_{34}=1, p_{41}=1, p_{18}=\alpha_{1} /\left(\lambda_{1}+\alpha_{1}\right), \\
& p_{84}=\lambda_{1} /\left(\lambda_{1}+\alpha_{2}\right), p_{80}=\alpha_{2} /\left(\lambda_{1}+\alpha_{2}\right), \\
& p_{10}^{(8)}=\alpha_{1} /\left(\lambda_{1}+\alpha_{1}\right) \cdot \alpha_{2} /\left(\lambda_{1}+\alpha_{2}\right), \\
& p_{11}^{(34)}=\lambda_{1} /\left(\lambda_{1}+\alpha_{1}\right), p_{11}^{(84)}=\frac{\alpha_{1}}{\left(\lambda_{1}+\alpha_{1}\right)} \cdot \frac{\lambda_{1}}{\left(\lambda_{1}+\alpha_{2}\right)}, \\
& \mu_{0}=1 /\left(\lambda_{2}+\lambda_{1}\right), m_{13}=\frac{\alpha_{1}}{\lambda_{1}+\alpha_{1}} \cdot 1 /\left(\lambda_{1}+\alpha_{1}\right), \\
& m_{18}=\frac{\alpha_{1}}{\lambda_{1}+\alpha_{1}} \cdot 1 /\left(\lambda_{1}+\alpha_{1}\right) \\
& m_{34}=1 / \alpha_{1}, m_{41}=1 / \alpha_{2}, m_{80}=\frac{\alpha_{1}+\alpha_{2}}{\left.\lambda_{1}+\alpha_{2}\right),} \\
& m_{84}=\frac{\lambda_{1}}{\lambda_{1}+\alpha_{2}} \cdot 1 /\left(\lambda_{1}+\alpha_{2}\right) \\
& M_{0}=\frac{1}{\lambda_{2}+\lambda_{1}}, M_{1}=\frac{1}{\alpha_{1}+\lambda_{1}}, W_{1}=\frac{1}{\alpha_{1}}
\end{aligned}
$$

\section{Graphical Interpretation}

By giving some numerical values to the parameters involved, various graphs has been plotted using particular case and the following interpretations have been drawn.

Figure 2 shows the behaviour operative unit for different values of repair rate $\left(\alpha_{1}\right)$. From the graph, we can see of MTSF with respect to failure rate $\left(\lambda_{1}\right)$ of the that the MTSF decreases as $\lambda_{1}$ increases, but has higher values for higher values of $\alpha_{1}$.

Figure 3 shows the behaviour of availability $\left(A_{0}\right)$ with respect to failure rate $\left(\lambda_{2}\right)$ of the operative unit for different values of repair rate $\left(\alpha_{2}\right)$. From the graph, we can see that the $A_{0}$ decreases as $\lambda_{2}$ increases, but has higher values for higher values of $\alpha_{2}$.

Figure 4 shows the behaviour of profit $(\mathrm{P})$ with respect to failure rate $\left(\lambda_{2}\right)$ of the operative unit for different values of repair rate $\left(\alpha_{2}\right)$. From the graph, we 


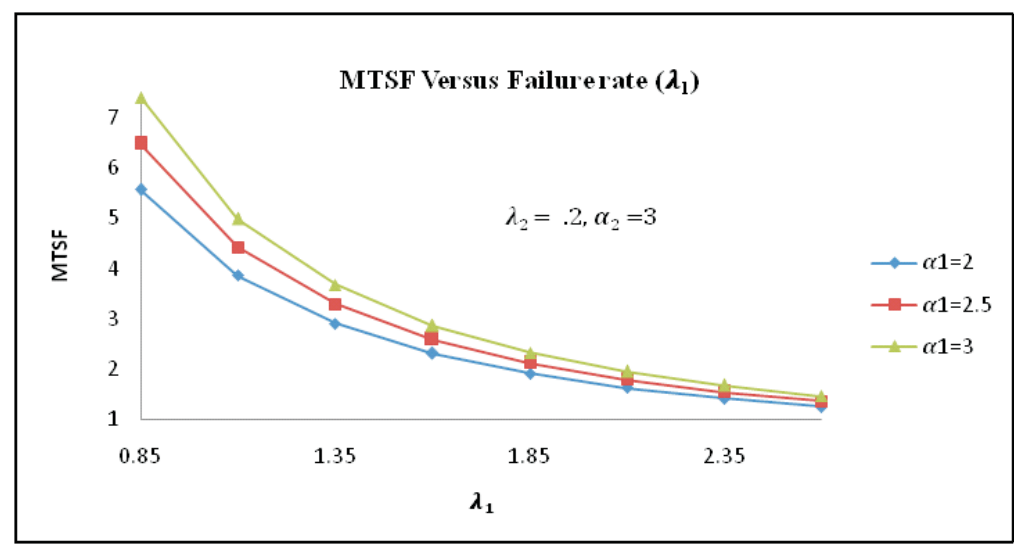

Figure 2

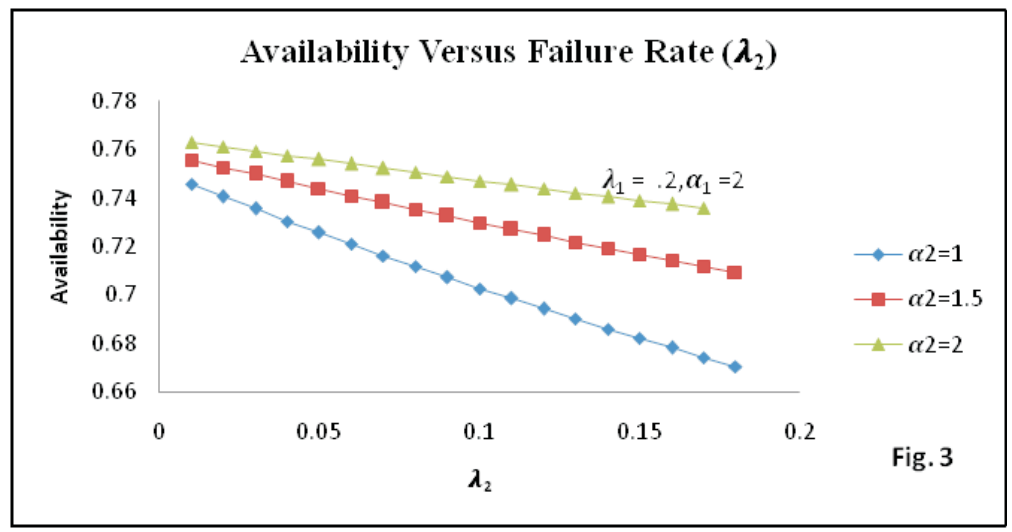

Figure 3

can see that the $\mathrm{P}$ decreases as $\lambda_{2}$ increases, but has higher values for higher values of $\alpha_{2}$.

Following conclusions can be drawn from Figure 3.5:

(i) If $\alpha=7$, then profit (P) is $>$ or $=$ or $<0$ according as failure rate $\left(\lambda_{2}\right)$ is $<$ or $=$ or $>1.67$. Therefore, the quality of the unit should be such that it has failure rate $\left(\lambda_{2}\right)$ less than 1.67 , otherwise the system will give negative profit.

(ii) If $\alpha_{2}=9$, then profit (P) is $>$ or $=$ or $<0$ according as failure rate $\left(\lambda_{2}\right)$ is $<$ or $=$ or $>1.802$. Therefore, the quality of the unit should be such that it has failure rate $\left(\lambda_{2}\right)$ less than 1.802 , otherwise the system will give 


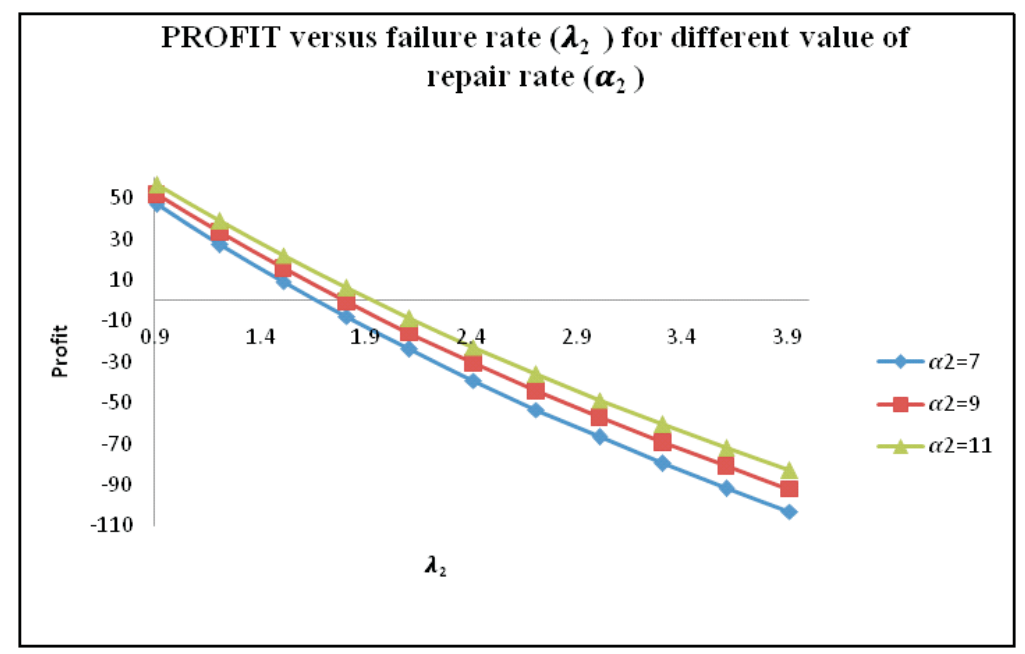

Figure 4

negative profit.

(iii) If $\alpha_{2}=11$, then profit $(\mathrm{P})$ is $>$ or $=$ or $<0$ according as failure rate $\left(\lambda_{2}\right)$ is $<$ or $=$ or $>1.935$. Therefore, the quality of the unit should be such that it has failure rate $\left(\lambda_{2}\right)$ less than 1.935 , otherwise the system will give negative profit.

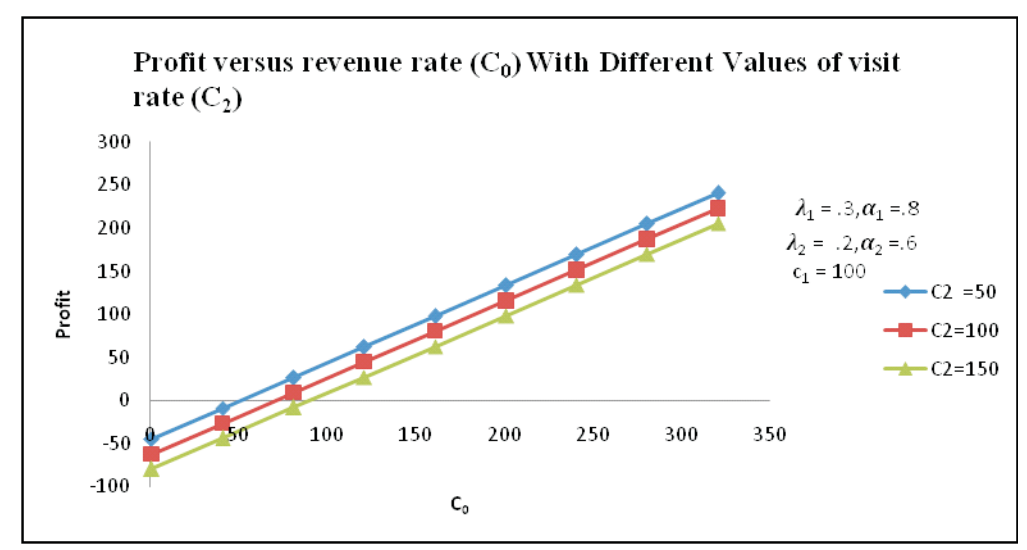

Figure 5

Figure 5 shows the behavior of profit $(\mathrm{P})$ with respect to cost per unit visit up revenue $\left(C_{0}\right)$ for different values of cost per visit $\left(C_{2}\right)$ of the repairman.It 
reaveals that profit $(\mathrm{P})$ increase with increase in the values of $C_{0}$, but it gets lowered for higher of $C_{2}$.

Following conclusions can also be drawn from the graph.

(i) For $C_{2}=50$, the profit $(\mathrm{P})$ is $>$ or $=$ or $<0$ according as $C_{0}$ is $>$ or $=$ or $<50.92$. Thus, the price of profit should be fixed in such a way so that the revenue is atleast 50.92 .

(ii) For $C_{2}=100$, the profit $\left(\mathrm{P}_{2}\right)$ is $>$ or $=$ or $<0$ according as $C_{0}$ is $>$ or $=$ or $<70.62$. Thus, the price of profit should be fixed in such a way so that the revenue is atleast 70.62 .

(iii) For $C_{2}=150$, the profit $\left(\mathrm{P}_{2}\right)$ is $>$ or $=$ or $<0$ according as $C_{0}$ is $>$ or $=$ or $<90.32$. Thus, the price of profit should be fixed in such a way so that the revenue is atleast 90.32 .

\section{References}

[1] L.R. Goel, G.C. Sharma and R. Gupta, Cost analysis of a two-unit cold standby system under different weather conditions, Microelectron Reliab., 25 (4) (1985), 655-659, doi: 10.1016/0026-2714(85)90395-6.

[2] R. Gupta and R. Goel, Profit analysis of a two-unit cold standby system with abnormal weather condition, Microelectronics Reliability, 31 (1) (1991), 1-5, doi: 10.1016/00262714(91)90336-6.

[3] R. Malhotra and G. Taneja, Comparative study between a single unit system and a twounit cold standby systemwith varying demand, Springer Plus, 4 (2015), 1-17, doi: 10.1186/s40064-015-1484-7.

[4] Osaki, Reliability analysis of a two-unit standby-redundant system with preventive maintenance, IEEE Transactions on Reliability, 21 (1972), 2429, doi: 10.1109/TR.1972.5216167.

[5] D. Singh and G. Taneja, Comparative of a Power Plant comprising one steamturbine with respect to two types of inspection, IJSCE, 6 (2014), 331-338.

[6] G. Taneja and R.K. Tuteja, Cost-benefit analysis of a two-server, two-unit, warm standby system with different types of failure, Microelectronics Reliability, 32 (1992), 1353-1359, doi: 10.1016/0026-2714(92)90002-3.

[7] G. Taneja, R.K. Tuteja and R.T. Arora, Analysis of two-unit system with partial failures and three types of repair, Reliability Engineering and System Safety, 33 (1991), 199-214, doi: 10.1016/0951-8320(91)90059-G. 